\title{
ALGORITMA NON-PHOTOREALISTIC RENDERING UNTUK KARTUN MENGGUNAKAN K-MEANS DAN CANNY
}

\author{
Non-Photorealistic Rendering Algorithm for Cartoons \\ Using K-Means and Canny
}

\author{
Budiman Baso ${ }^{1)}$ Irit Maulana Sapta ${ }^{2)}$ Saniyatul Mawaddah ${ }^{3)}$ \\ 1) Program Studi Teknologi Informasi, Fakultas Pertanian, Universitas Timor \\ Jl. Km. 09, Kelurahan Sasi, Kecamantan Kota Kefamemanu, TTU, NTT, 85613 \\ 2) Semesta Bilingual Boarding School Semarang \\ Jl. Setia Budi No.116, Srondol Kulon, Kec. Banyumanik, Kota Semarang, Jawa Tengah 50269 \\ 3) Program Studi D3 Teknik Informatika PSDKU Lamongan, Departemen Informatika, PENS \\ Jl. Panglima Sudirman, No.125 Lamongan, Jawa Timur 62212
} Copyright (C2021, JITU, Submitted: 29 Desember 2020; Revised: 06 Januari 2021; Accepted: 03 Februari 2021;
Published: 01 Maret 2021

\begin{abstract}
Cartoons are one type of illustration usually in a non-realistic or semi-realistic style. To make a cartoon drawing manually requires good drawing ability. So, not everyone can make cartoons. This research proposes a non-photorealistic rendering algorithm to create cartoon drawings automatically. The algorithm consists of four phases. First, create an image abstraction using bilateral filtering. Second, using kmeans clustering for abstract image quantization. Third, get the contour lines of the drawing using the canny algorithm. Fourth, contour lines and quantized images are combined. The results show that this algorithm can produce good visualization of cartoon images.
\end{abstract}

Keywords - non photorealistic rendering, cartoon, quantization, canny.

\begin{abstract}
Abstrak - Kartun adalah salah satu tipe dari ilustrasi biasanya dalam gaya non-realistis atau semi-realistis. Untuk membuat gambar kartun secara manual dibutuhkan kemampuan menggambar yang baik. Jadi, tidak semua orang dapat membuat gambar kartun. Penelitian ini mengajukan suatu algoritma Non-Photorealistic Rendering untuk membuat gambar kartun secara otomatis. Algoritma ini terdiri dari empat fase. Pertama, membuat abstraksi gambar menggunakan bilateral filtering. Kedua, menggunakan kmeans clustering untuk kuantisasi gambar abstrak. Ketiga, mendapatkan garis kontur dari gambar menggunakan algoritma canny. Keempat, garis kontur dan gambar terkuantisasi digabungkan. Hasilnya menunjukkan bahwa algoritma ini dapat menghasilkan visualisasi gambar kartun yang baik.
\end{abstract}

Kata kunci - non photorealistic rendering, gambar kartun, kuantisasi warna, deteksi tepi canny.

\section{Pendahuluan}

Non Photorealistic Rendering (NPR) adalah teknik dalam memanipulasi sebuah citra atau gambar realis menjadi tidak realis, dapat menciptakan sebuah citra yang berbeda dari aslinya. Render non-fotorealistik mengacu pada penggunaan komputer yang menghasilkan gambar non-fotorealistis dengan teknologi grafis (Lu et al., 2013). Non-Photorealistic Rendering (NPR) merupakan bidang computer graphic yang fokus pada berbagai kemungkinan gaya ekspresif untuk digital art yang terinspirasi oleh gaya artistik seperti melukis, menggambar dan animasi kartun. Non Photorealistic Rendering (NPR) juga di terapkan dalam film, video game, ilustrasi arsitektur, dan animasi eksperimental dalam bentuk toon shading atau arsiran kartun (Kang, Lee and Chui, 2007). Non Photorealistic Rendering (NPR) adalah teknik untuk memanipulasi sebuah citra atau gambar realis menjadi tidak realis, dapat

*) Penulis Korespondensi ( Budiman Baso)

Email: budimanbaso@gmail.com menciptakan sebuah citra yang berbeda dari aslinya (Rosyidi et al., 2013).

Dalam menghasilkan efek kartun pada citra dengan menggunakan teknik Non-Photorealistic Rendering (NPR), algoritma yang di gunakan merupakan aspek penting dalam mendapatkan hasil dengan karakter estetika seni dan visualisasi yang lebih baik. Pada

penelitian rendering kartun yang telah ada misalnya, (Lu et al., 2013) mengabstraksi gambar melalui filter bilateral, selanjutnya mentransfer ruang warna dari gambar yang diabstraksikan dari RGB ke L $\alpha \beta$, mengekstraksi informasi pencahayaan dari saluran $\mathrm{L}$ dan melakukan pemrosesan terkuantisasi, dan menggabungkan saluran luminance terkuantisasi dengan saluran $\alpha$ dan saluran $\beta$, sehingga memperoleh gambar terkuantisasi. Terakhir, filter FDOG digunakan untuk mengekstrak kontur gambar yang kontinyu dan halus, gambar yang telah dikuantifikasi dan gambar kontur disatukan untuk menghasilkan gambar kartun.

(Kang, Lee and Chui, 2007) menyajikan teknik rendering non fotorealistik yang secara otomatis memberikan abstraksi bergaya dari sebuah citra. 
Pendekatannya didasarkan pada bentuk / filter warna yang dipandu oleh bidang vektor yang menggambarkan aliran fitur yang menonjol dalam gambar. Aliran ini berbasis filter secara signifikan meningkatkan kinerja abstraksi dalam hal peningkatan fitur dan stilisasi. Metode ini sederhana dan mudah diimplementasikan. Hasil eksperimen menunjukkan efektivitas metode ini dalam menghasilkan gaya dan peningkatan fitur ilustrasi dari foto.

(Guastella and Valenti, 2016) menjelaskan filter kartun melalui adaptive abstraction, metodologi abstraksi sederhana namun efektif yang dibuat oleh pipeline. Gagasan yang mendasari algoritma yang diusulkan terdiri dalam mengidentifikasi tepi, dengan redundant wavelet transform, dan dalam mengaburkan bagianbagian dalam komponen digunakan adaptive cir-cular median filter. Hasil filter kartun melalui adaptive abstraction yang didapatkan dari eksperimen ini cukup baik.

Berdasarkan karakteristik gambar kartun, pada penelitian ini gambar input diabstraksikan melalui filter bilateral terlebih dahulu untuk mendapatkan kenaikan kontras. Langkah kedua gambar yang telah diabstraksikan lalu distilisasi (proses pengolahan yang mengarah pada bentuk yang indah) dengan kuantisasi warna yang lebih halus dengan menggunakan Kmeans. Ketiga, mengekstraksi garis batas gambar yang diabstraksikan oleh canny dilanjutkan dengan filter ratarata untuk lebih meningkatkan visual lukisan kartun. Langkah terakhir, gambar yang telah terkuantisasi disatukan dengan gambar tepi untuk mendapatkan efek kartun dengan warna yang lebih halus, visibilitas yang lebih tinggi, dan kurang mendetail.

\section{Metode PENELitian}

Penelitian ini terdiri dari empat fase yakni abstraksi gambar, kuantisasi warna gambar, mendapatkan garis kontur dari gambar, serta menggabungkan hasil kuantisasi gambar dengan garis kontur. Tahapan alur algoritma ini dapat dilihat dalam gambar 1 .

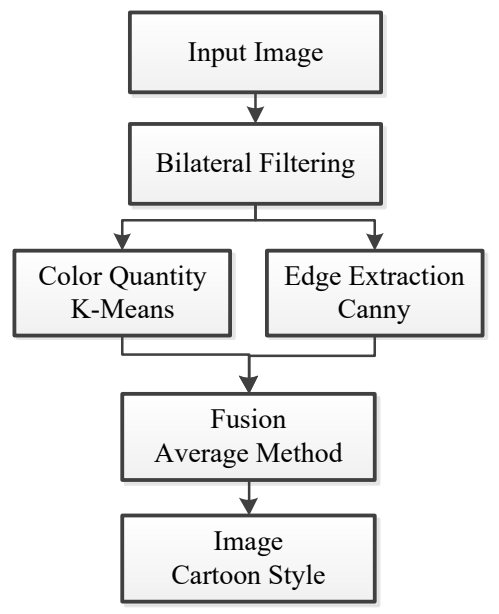

Gambar 1. Flowchart Algoritma

\section{A. Abstraksi Gambar Menggunakan Bilateral Filtering}

Tahap awal dalam penelitian ini adalah proses abstraksi gambar. Abstraksi gambar merupakan teknik meningkatkan kontras gambar dan mengabaikan detail gambar yang tidak penting. Ini digunakan untuk mengirimkan informasi visual dapat menarik lebih banyak perhatian orang dan mempromosikan efek transfer informasi (Lu et al., 2013). Abstraksi gambar dilakukan menggunakan bilateral filtering.

Bilateral filtering adalah teknik filtering yang pertama kali diajukan oleh Tomasi dan Mandhuci (Tomasi and Manduchi, 1998). Filter bilateral adalah filter difusi nonlinier yang dapat mengaburkan sinyal kecil dan non-kontinu dan dapat mempertajam informasi tepi. Tidak hanya mempertimbangkan jarak ruang tetapi juga perbedaan intensitas sinyal (Lu et al., 2013). Langkah yang dilakukan untuk menghasilkan gambar abstrak dengan filter bilateral, pertama inisialisasi gambar input dengan $\mathrm{f}($.) dan $\mathrm{H}$ (.) adalah filter yang digunakan untuk memproses gambar input agar menjadi gambar abstrak, seperti ditunjukkan pada persamaan (1)

$$
H\left(\widehat{x}, \sigma_{d}, \sigma_{r}\right)=\frac{\int e^{-\frac{1}{2}\left(\frac{\|\widehat{x}-x\|}{\sigma_{d}}\right)^{2}} w\left(x, \widehat{x}, \sigma_{r}\right) f(x) d x}{\int e^{-\frac{1}{2}\left(\frac{\|\widehat{x}-x\|}{\sigma_{d}}\right)^{2}} w\left(x, \widehat{x}, \sigma_{r}\right) d x}
$$

Dalam formulasi ini,

$$
w\left(x, \widehat{x}, \sigma_{r}\right)=e^{-\frac{1}{2}\left(\frac{\|x-x\|}{\sigma_{d}}\right)^{2}}
$$

$\hat{x}$ adalah lokasi piksel, $x$ adalah piksel tetangga, dan $\sigma_{d}$ adalah radius buram. Jika $\sigma_{d}$ terlalu besar, filter akan menjadi tidak berpengaruh pada gambar dan apabila nilai $\sigma_{r}$ terlalu kecil, $\sigma_{r}$ menentukan tingkatan menjaga atau mengaburkan gambar. Hasil dari abstraksi gambar dapat dilihat dalam gambar 2 .
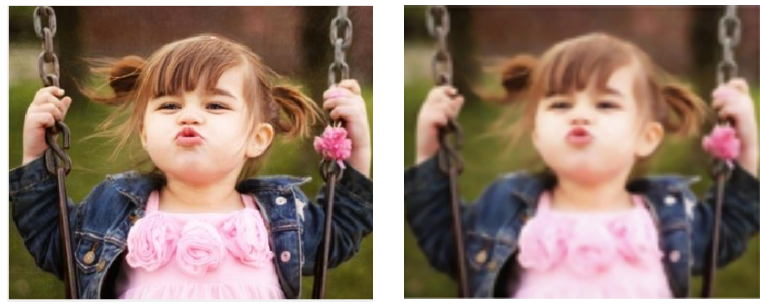

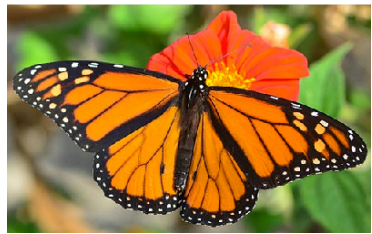

(a)

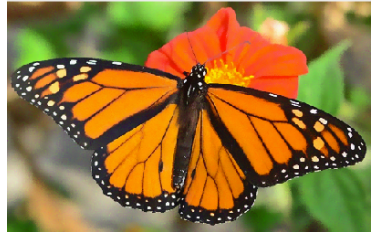

(b)
Gambar 2. (a) Gambar asli dan (b) Efek abstrak 


\section{B. Kuantisasi Warna Menggunakan K-Means}

Kuantisasi warna merupakan proses mengurangi jumlah warna berbeda yang digunakan dalam sebuah citra dengan harapan secara kasat mata citra baru secara visual mirip dengan gambar asli. Setelah proses abstraksi, banyak informasi detail dalam gambar asli dihilangkan, dan warna pada wilayah yang luas menjadi dekat satu sama lain atau ditransisikan. Untuk mendapatkan efek pewarnaan kartun, dilakukan proses kuantisasi pada gambar yang telah diabstraksi dengan menggunakan algoritma kmeans.

Gambar hasil abstraksi, kemudian digunakan sebagai data input untuk menjalani algoritma kuantisasi warna KMeans untuk mengkuantisasi citra ke dalam beberapa warna (Palus, 2004). Algoritma K-Means mencoba memisahkan sampel dalam kelompok n-warna dengan varians yang sama. Diagram alur untuk algoritma disajikan pada Gambar 3.

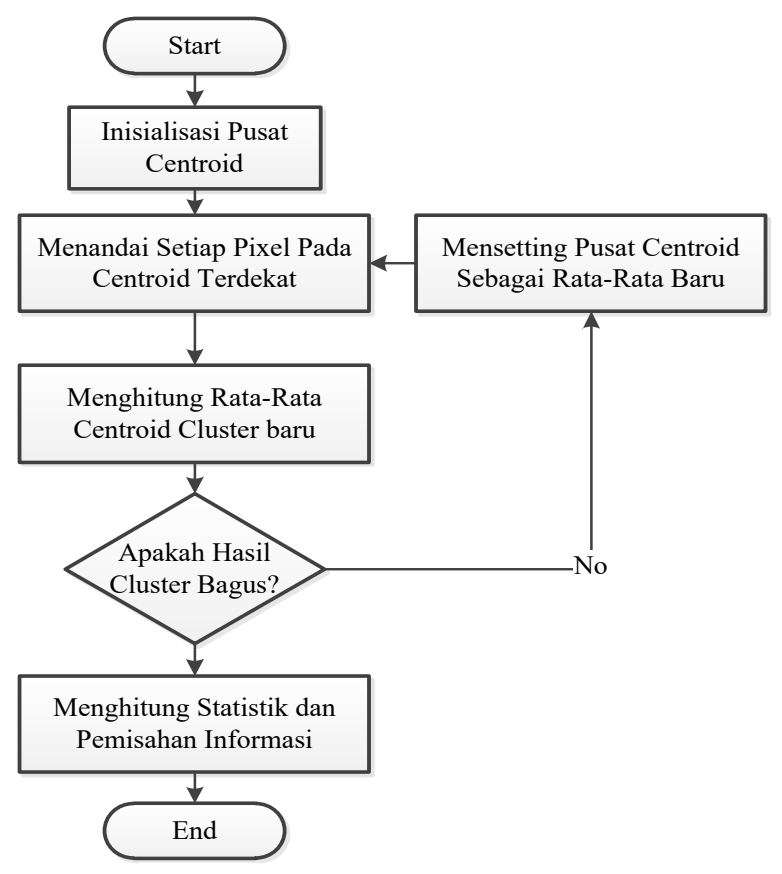

Gambar 3. Flow chart algoritma Kmeans

Secara umum, algoritma ini menerima beberapa parameter awal untuk menentukan jumlah kluster awal dan kemudian secara otomatis menempatkan pusat kluster di ruang fitur multidimensi. karena penelitian ini menggunakan data gambar, maka titik datanya berupa pixel. masing-masing pixel dalam gambar didistribusikan ke kluster yang memiliki vektor rata-rata terdekat. Jika semua piksel sudah diklasifikasi, dihitung vektor ratarata untuk setiap kluster. vektor ini digunakan secara iteratif untuk klasifikasi pixel menggunakan kriteria vektor rata-rata terdekat. langkah ini berulang sampai tidak ada perubahan yang signifikan. Tabel 1 adalah contoh ketika sebuah gambar dikuantisasi menggunakan KMeans. Hasil menunjukkan bahwa jumlah kelompok yang ditetapkan adalah jumlah warna yang dikuantifikasi oleh algoritma.
Tabel 1 Hasil Kuantisasi menggunakan K-Means

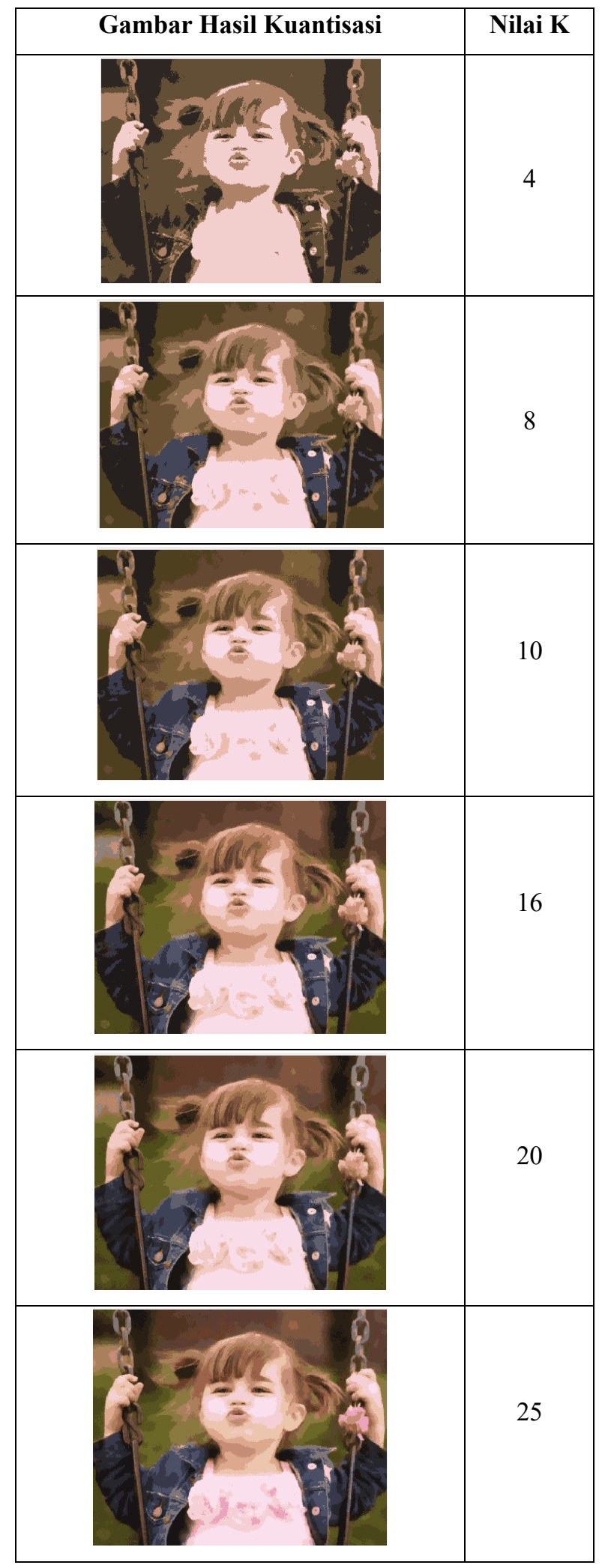

\section{Ekstraksi Tepi}

Garis kontur yang jelas adalah fitur penting pada gambar kartun. Pada penelitian ini, filter Canny (Yuan and $\mathrm{Xu}, 2015$ ) digunakan untuk mengekstrak garis kontur dari gambar yang sudah dilakukan abstraksi. Langkah- 
langkah mengekstraksi kontur gambar dengan filter Canny adalah sebagai berikut:

Untuk mencegah noise salah dideteksi sebagai tepian, maka noise harus dikurangi terlebih dahulu, oleh karena itu pada langkah pertama gambar harus diperhalus dengan mengggunakan Gaussian filter, ditunjukkan pada persamaan (3).

\begin{tabular}{|c|c|c|c|c|c|}
\hline \multirow{5}{*}{$1 / 159$} & 2 & 4 & 5 & 4 & 2 \\
\hline & 4 & 9 & 12 & 9 & 4 \\
\hline & 5 & 12 & 15 & 12 & 5 \\
\hline & 4 & 9 & 12 & 9 & 4 \\
\hline & 2 & 4 & 5 & 4 & 2 \\
\hline
\end{tabular}

Setelah noise dihilangkan pada proses smoothing, dilakukan proses untuk mendapatkan kekuatan tepi. Tepian harus ditandai pada gambar yang memiliki gradien yang besar. Digunakan operator gradien dan dilakukan pencarian secara horizontal dan vertikal. Hal tersebut ditunjukkan dalam Persamaan (4).

$$
\mathrm{G}_{\mathrm{x}}=\begin{array}{|c|c|c|}
\hline-1 & 0 & +1 \\
\hline-2 & 0 & +2 \\
\hline-1 & 0 & +1 \\
\hline
\end{array} \quad \mathrm{G}_{\mathrm{y}}=\begin{array}{|c|c|c|c|}
\hline+1 & +2 & +1 \\
\hline 0 & 0 & 0 \\
\hline-1 & -2 & -1- \\
\hline
\end{array}
$$

Magnitudo gradien atau juga dikenal sebagai kekuatan tepi dapat ditentukan sebagai jarak euclidean, seperti yang ditunjukkan dalam Persamaan (5). Hasil dari kedua operator digabungkan dengan rumus:

$$
G=S Q R T\left(G_{x}^{2}+G_{y}^{2}\right)
$$

Dimana; Gx dan Gy adalah gradien pada masingmasing arah $\mathrm{x}$ dan $\mathrm{y}$. Untuk menentukan tepian yang sebenarnya ini, arah tepian harus ditentukan dan disimpan seperti ditunjukkan dalam Persamaan (6). Setelah arah tepi diperoleh, perlu menghubungkan antara arah tepi dengan sebuah arah yang dapat dilacak dari citra.

$$
\theta=\arctan \left(\frac{\mathrm{G}_{\mathrm{y}}}{\mathrm{G}_{\mathrm{x}}}\right)
$$

Selanjutnya penghilangan non-maximum dilakukan di sepanjang tepi dan menghilangkan piksel - piksel yang tidak dianggap sebagai tepi. Hanya nilai maksimum yang ditandai sebagai tepi. Sehingga didapatkan garis tepi yang lebih ramping.

Untuk membuat gambar biner, diterapkan dua buah thresholding yaitu low thresholding (T1) dan high thresholding (T2). Nilai yang kurang dari T1 akan diubah menjadi hitam (nilai 0) dan nilai yang lebih dari T2 diubah menjadi putih nilai 255). Dan yang terakhir adalah Edge Trancking dimana tepian final ditentukan dengan menekan semua sisi yang tidak terhubung dengan tepian yang kuat. Semua piksel yang terhubung dengan piksel putih yang memiliki nilai lebih besar dari $\mathrm{T} 1$ juga dianggap sebagai tepi.
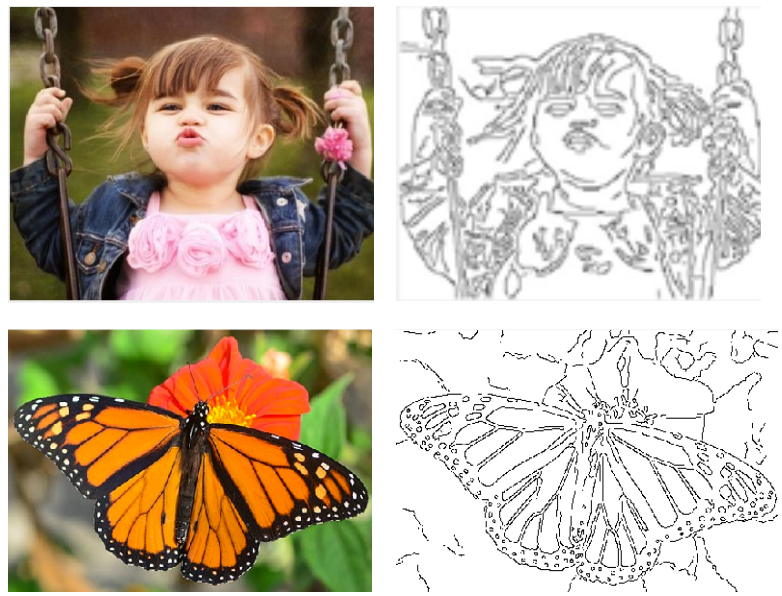

Gambar 3. Ekstraksi tepi dengan canny

\section{E. Fusion}

Setelah proses ekstraksi kuantitatif menggunakan Kmeans dan ekstraksi tepi dengan canny dan proses penghalusan tepi denga mean filter, gambar yang terkuantisasi digabungkan dengan tepi yang diekstraksi dengan menggunakan fusion average method (Mule, 2015), (Malviya and Bhirud, 2009). Metode ini (Rani and Sharma, 2013) menghasilkan gambar yang fokus pada semua wilayahnya. Karena rata-rata nilai piksel dari kedua gambar input dihitung, nilai piksel dari setiap gambar diambil dan ditambahkan. Kemudian nilai ini dibagi dengan jumlah gambar input untuk mendapatkan nilai rata-rata. Nilai rata-rata yg diperoleh ini kemudian digunakan untuk menentukan piksel yg sesuai dengan gambar output/gambar hasil. Pada Gambar X (a) adalah gambar tepi dari gambar asli yang disaring secara bilateral dan diekstraksi oleh Canny, (b) adalah gambar efek yang menggabungkan efek tepi gambar dan gambar efek dengan filter bilateral dan gambar yang terkuantisasi lembut oleh tingkat kuantisasi dengan Kmeans (Palus, 2004). Gambar yang diperoleh ditunjukkan sebagai Gambar 4.
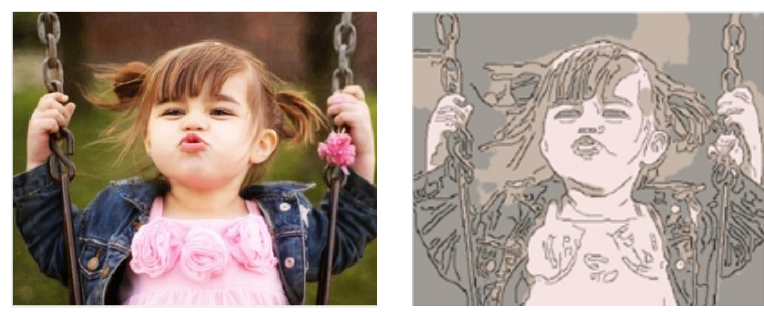

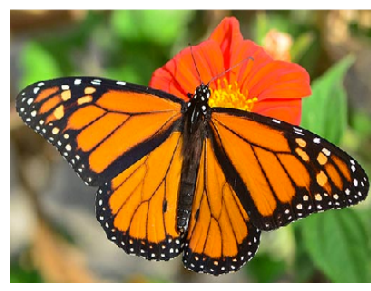

(a)

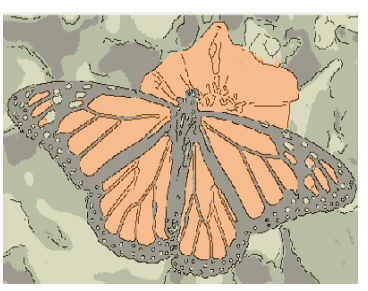

(b)
Gambar 4. (a) Gambar Input dan (b) Hasil Gambar Cartoon rendering 


\section{HASIL DAN PEMBAHASAN}

Pada penelitian ini, di bangun dengan menggunakan Matlab. Dengan tampilan user interface yang interaktif berbasis Graphic User Interface, user dimungkinkan dapat memilih parameter initial centroid K-Means, Dimensi Mean Filter serta metode. Uji coba pada penelitian ini dilakukan pada beberapa citra asli. Gambar 8 adalah hasil percobaan dari dua gambar lainnya yang terdiri dari gambar asli, gambar hasil bilateral filter, gambar hasil kuantisasi dengan K-Means, gambar hasil edge extraction dengan Canny dan gambar hasil akhir.
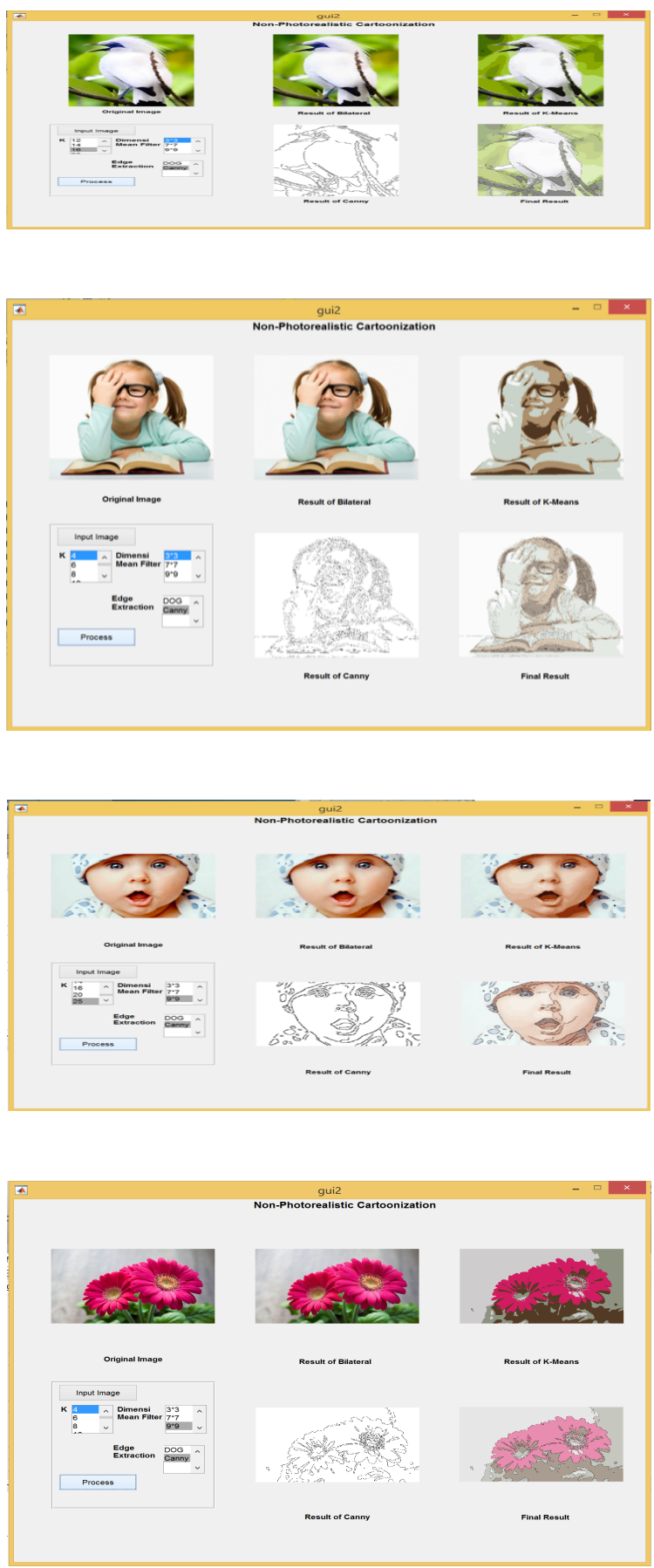

Gambar 4. Hasil Uji Coba

\section{KESIMPULAN}

Penelitian ini mempelajari tentang teknologi NonPhotorealistic Rendering untuk menciptakan gambar kartun. Algoritma ini dapat secara otomatis menghasilkan gambar kartun tanpa partisipasi user dan keterampilan menggambar. Pertama, dilakukan abstraksi gambar menggunakan bilateral filtering. Kedua, dilakukan kuantisasi pada gambar yang telah diabstraksi dengan menggunakan algoritma kmeans. Ketiga, menggunakan filter Canny untuk mengekstraki garis kontur gambar secara halus dan bersambung. Algoritma ini menghasilkan visualisasi gambar kartun yang lebih baik.

\section{DAFTAR PUSTAKA}

[1] GUASTELlA, D. AND VALENTI, C., 2016. Cartoon filter via adaptive abstraction. Journal of Visual Communication and Image Representation, [online] 36, pp.149-158. Available at: $<$ http://dx.doi.org/10.1016/j.jvcir.2016.01.012>.

[2] Rosyidi, M. Suyanto, Amir F.S., 2014. Penerapan Teknik Non-Photorealistic Rendering (NPR) Dalam Pembuatan Efek Warna Goresan Pensil Pada Citra.

[3] KANG, H., LEE, S. AND CHUI, C.K., 2007. Coherent line drawing. Proc. NPAR, [online] 1(212), pp.43-50. Available $<$ http://doi.acm.org/10.1145/1274871.1274878>.

[4] LU, L., PU, Y., ZHANG, H. AND XU, D., 2013. A Nonphotorealistic Rendering Algorithm For Cartoons. 2(Cisp), pp.680-685.

[5] MALVIYA, A. AND BHIRUD, S.G., 2009. MultiFocus Image Fusion of Digital Images. 2009 International Conference on Advances in Recent Technologies in Communication and Computing, [online] pp.887-889. Available at: $<$ http://ieeexplore.ieee.org/document/5328453/>.

[6] MULE, M.B., 2015. Basic Medical Image Fusion Methods. International Journal of Advanced Research in Computer Engineering \& Technology (IJARCET), 4(3), pp.1046-1049.

[7] PALUS, H., 2004. On Color Image Quantization by the KMeans Algorithm.

[8] RANI, K. AND SHARMA, R., 2013. Study of Different Image fusion Algorithm. International Journal of Emerging Technology and Advanced Engineering (ISSN 2250-2459, ISO 9001:2008 Certified Journal, Volume 3, Issue 5, May 2013, 3(5), pp.288-291.

[9] TOMASI, C. AND MANDUCHI, R., 1998. Bilateral filtering for gray and color images. Sixth International Conference on Computer Vision (IEEE Cat. No.98CH36271), [online] pp.839-846. Available at: $<\mathrm{http} / / /$ ieeexplore.iee. org/document/710815/>.

[10] YUAN, L. AND XU, X., 2015. Adaptive Image Edge Detection Algorithm Based on Canny Operator. 2015 4th International Conference on Advanced Information Technology and Sensor Application (AITS), [online] (2), pp.28-31. Available a t: $<\mathrm{http}$ ://ieeexplore.ieee.org/document/ 